\title{
An atypical mood elevator
}

\author{
Henry R. Rollin
}

It was a particularly long and seemingly endless, cheerless out-patients' clinic. Then, out of the blue, my depressed spirits were elevated by the one, acid comment spat out by a care-worn Cockney lady who, as it emerged, was being emotionally sucked dry by the tantrums of her snivelling offspring - the patient.
"It's no good talking to "im, doctor", she said jerking an hyper-extended thumb into the direction of the sniveller. "It just runs like duck's water off 'is back".

Henry R. Rollin, Emeritus Consultant Psychiatrist, Horton Hospital, Epsom, Surrey

\section{Corrigenda}

Psychiatric Bulletin, 22, 773-781. The title and second paragraph of column one, page 776 should read: Professor James Griffith Edwards (introduced by Professor Hamid Ghodse). Professor James Griffith Edwards is Emeritus Professor of Addiction Behaviour at the Institute of Psychiatry and Emeritus Consultant Psychiatrist at the Bethlem Royal and Maudsley Hospitals.
Professor Hugh Lionel Freeman (introduced by Henry R. Rollin) - the second paragraph of column one, page $\mathbf{7 7 8}$ should read:

So many indeed are his talents and so praiseworthy are they all that it would be idle for me to attempt to assess them, or to arrange them in any sort of rank order. 